๑) В. М. Сеньківський, д.т.н., професор, І. В. Піх, к.Т.н., доцент, Т. С. Голубник, асистент, Ю. І. Петрів, аспірант, Львів, УАД

\title{
ПОБУДОВА ФУНКЦІЙ НАЛЕЖНОСТІ ФАКТОРІВ ЯКОСТІ ФОРМУВАННЯ МОНТАЖНИХ СПУСКІВ
}

Запроектовано функції приналежності та здійснено їх графічне відображення для виділених чинників впливу на якість формування монтажних спусків книжкових видань. Побудовано матриці парних порівнянь, що враховують експертами певні ранги факторів, за допомогою яких розраховано значення функцій приналежності для запропонованих лінгвістичних термів в точках ділення універсальної множини значень лінгвістичних змінних. Здійснено формалізоване відображення лінгвістичного терма «якість монтажного спуску" за допомогою нечіткої множини, що містить значення функцій приналежності. Наведено приклад графічного відображення значень функцій приналежності лінгвістичної змінної “обсяг видання".

Ключові слова: монтажний спуск, якість, фактор, лінгвістична змінна, функція належності, терм-множина, матриця, ранг.

\section{Вступ}

Якість друкованої продукції значною мірою залежить від рівня формування монтажних спусків - однієї з основних процедур додрукарського підготування книжкових видань. Важливим завданням при цьому $€$ прогнозоване встановлення теоретично обґрунтованих значень технологічних параметрів (у нашому дослідженні факторів) формування монтажних спусків як за пріоритетністю впливу на процес, так і за числовим ваговим вираженням [1]. Аргументовану відповідь при вирішенні цього завдання можна отримати, використавши за- соби нечіткої логіки [2-7] та дослідження операцій $[8,9]$. у загальному трактуванні нечітка логіка рівнозначна теорії нечітких множин, характерною ознакою яких $€$ певна нечіткість (з огляду на норми у традиційній математиці) та розмитість (на початковому етапі) меж задання області значень параметрів [3].

\section{Постановка проблеми}

Процедуру формування спуску вважатимемо деякою функцією [10],

$\mathrm{PR}=\mathrm{F}\left(\mathrm{s}_{1}, \mathrm{~s}_{2}, \mathrm{~s}_{3}, \mathrm{~s}_{4}, \mathrm{~s}_{5}, \mathrm{~s}_{6}, \mathrm{~s}_{7}, \mathrm{~s}_{8}\right),(1)$ з аргументами-факторами: $\mathrm{s}_{1}$ обсяг видання; $s_{2}-$ тип дру-

(c) $2014 \mathrm{p}$. 
карської машини; $\mathrm{s}_{3}-$ спосіб комплектування; $\mathrm{s}_{4}-$ розкладання звороту; $\mathrm{s}_{5}-$ тип скріплення блоку; $\mathrm{s}_{6}$ - тип зошита; $\mathrm{s}_{7}-$ фальцювання; $\mathrm{s}_{8}-$ формат видання.

Завдання у загальному вигляді сформулюємо таким чином. Вважатимемо якість формування монтажного спуску лінгвістичним термом $\mathrm{P}$, який виражається через кількісні (при їх наявності) або якісні значення наведених вище факторів нечітких лінгвістичних змінних (ЛЗ). Для формалізованого подання терму $\mathrm{P}$ використаємо універсальну нечітку множину $\mathrm{D}=\left\{\mathrm{d}_{1}, \mathrm{~d}_{2}, \ldots, \mathrm{d}_{\mathrm{n}}\right\}$, на якій задаються перераховані вище ЛЗ та ранги $r_{p}\left(d_{i}\right)$, що визначають пріоритетність лінгвістичних термів (ЛТ) на квантах (частинах) поділу універсальної множини значень у встановлених діапазонах $\mathrm{d}_{\mathrm{i}}(\mathrm{i}=1, \ldots, \mathrm{n})$. У peзультаті формалізоване подання ЛТ «якість монтажного спуску» $\mathrm{P}$ можна зобразити нечіткою множиною, елементи якої містять сукупності пар [3, 5]:

$$
P_{F}=\left\{\begin{array}{l}
\frac{\mu_{p}\left(d_{1}\right)}{d_{1}}, \frac{\mu_{p}\left(d_{2}\right)}{d_{2}}, \ldots, \\
\frac{\mu_{p}\left(d_{n}\right)}{d_{n}}
\end{array}\right\},
$$

де: $\mathrm{P}_{\mathrm{F}} \subset \mathrm{D} ; \mu_{\mathrm{p}}\left(\mathrm{d}_{\mathrm{i}}\right)-$ міра належності до множини $\mathrm{P}_{F}$ элемента $\mathrm{d}_{\mathrm{i}} \in \mathrm{D}$.

Сукупність значень $\mu_{\mathrm{p}}\left(\mathrm{d}_{\mathrm{i}}\right)$, пов'язаних між собою логічними операціями $\wedge$ та $\vee$, забезпечить отримання числового вираження шуканої функції належності лінгвістичного терму $\mathrm{P}$ якості монтажного спуску.

\section{Результати проведених досліджень}

у загальному випадку розподіл мір належності має такий вигляд:

$$
\frac{\mu_{1}}{r_{1}}=\frac{\mu_{2}}{r_{2}}=\ldots \frac{\mu_{n}}{r_{n}},
$$

де $\mu_{\mathrm{i}}=\mu_{\mathrm{p}}\left(\mathrm{d}_{\mathrm{i}}\right) ; r_{\mathrm{i}}=r_{\mathrm{p}}\left(\mathrm{d}_{\mathrm{i}}\right)$ для всіх $\mathrm{i}=1, \ldots, \mathrm{n} ; \mu_{1}+\mu_{2}+\ldots+\mu_{\mathrm{n}}=1$.

Відомо, що для встановлених рангів факторів числові значення функцій належності отримують із співвідношень $[3,5]$ :

$$
\left.\begin{array}{l}
\mu_{1}=\left(1+\frac{r_{2}}{r_{1}}+\frac{r_{3}}{r_{1}}+\ldots+\frac{r_{n}}{r_{1}}\right)^{-1} ; \\
\mu_{2}=\left(\frac{r_{1}}{r_{2}}+1+\frac{r_{3}}{r_{2}}+\ldots+\frac{r_{n}}{r_{2}}\right)^{-1} ; \\
\mu_{n}=\left(\frac{r_{1}}{r_{n}}+\frac{r_{2}}{r_{n}}+\frac{r_{3}}{r_{n}}+\ldots+1\right)^{-1} \cdot
\end{array}\right\}
$$

Діапазон можливих значень ЛЗ, що ідентифікують виокремлені фактори, умовно розділяємо на чотири частини, кількість яких достатня для графічного відтворення якісних ЛТ за п'ятьма точками поділу. Таким чином, відносні оцінки рангів лінгвістичних термів утворюють квадратну обернено симетричну матрицю $A=a_{i j}$, де $a_{i j}=r_{i} / r_{j}$ для $\mathrm{i}, j=1, \ldots, 5$.

На підставі сказаного та висловлених умов і застережень завдання дослідження подамо аналітичним формулюванням: 


$$
\left.\begin{array}{l}
P_{F}=F\left(x_{j}, y_{k}, z\right) \rightarrow \max , \\
j=\overline{1,4} ; k=\overline{1,3} ; \\
x_{j}>0, y_{k}>0, z>0 ; \\
\mu_{p}\left(d_{i}\right) \rightarrow \max , d_{i} \in D, \\
P_{F} \subset D, i=\overline{1,5} .
\end{array}\right\}
$$

Згідно (5) необхідно досягти максимального значення функції, що визначає якість монтажного спуску, при додатних значеннях ЛТ, заданих універсальною терм-множиною, і максимальних значеннях функцій належності термів оцінювання лз.

Остаточно числові значення функцій належності при встановлених рангах лінгвістичних термів у п'яти точках поділу універсальної множини отримаємо у результаті опрацювання матриці [11]:

$$
A=\left[\begin{array}{lllll}
1 & \frac{r_{2}}{r_{1}} & \frac{r_{3}}{r_{1}} & \frac{r_{4}}{r_{1}} & \frac{r_{5}}{r_{1}} \\
\frac{r_{1}}{r_{2}} & 1 & \frac{r_{3}}{r_{2}} & \frac{r_{4}}{r_{2}} & \frac{r_{5}}{r_{2}} \\
\cdots & \cdots & \cdots & \cdots & \cdots \\
\frac{r_{1}}{r_{5}} & \frac{r_{2}}{r_{5}} & \frac{r_{3}}{r_{5}} & \frac{r_{4}}{r_{5}} & 1
\end{array}\right] .
$$

Якщо ранги невідомі, доцільно скористатися матрицею попарних порівнянь для кожного із заданих лінгвістичних термів. Елементи такої матриці отримують на підставі шкали відносної важливості об'єктів [11], яка містить дев'ять порівняльних оцінок, кожна з яких відтворює ступінь переваги між аналізованими об'єктами. При цьому, для двох об'єктів (наприклад, $\mathrm{k}_{1}$ i k $\mathrm{k}_{2}$ ) залежно від їх важливості та міри впливу матимемо пропоновані значення відповідного елемента матриці попарних порівнянь у позиції $\left(\mathrm{k}_{1}, \mathrm{k}_{2}\right)$. Матриця квадратна, обернено симетрична, транзитивна.

Опрацювання матриці за програмою «Імітаційне моделювання в системному аналізі методом бінарних порівнянь» [12] забезпечує отримання власного вектора матриці попарних порівнянь, компоненти якого відтворюють ранги ЛТ факторів. Одночасно 3 використанням співвідношень (4) обчислюються значення функцій належності $\mu_{\mathrm{i}}$ для кожного з термів, заданих у табл.

Задамо умовні місця поділу проміжку можливих значень ЛЗ в універсальній множині точками $\left(\mathrm{d}_{1}, \mathrm{~d}_{2}, \mathrm{~d}_{3}, \mathrm{~d}_{4}, \mathrm{~d}_{5}\right)$. Для нашого завдання вважатимемо, що ранги ЛТ відомі, тобто отримані на основі експертних суджень спеціалістів поліграфічного профілю.

Наведемо приклад побудови та розрахунку функцій належності для фактора «обсяг видання».

Враховуючи (6) та висловлені зауваження, будуємо матриці А для лінгвістичної змінної $\mathrm{x}_{1}$ "обсяг видання». Універсальна множина згідно табл. та експертних суджень складатиметься з таких точок поділу: $D=\{2,8$, 14, 18, 24\}. Терм-множина значень $\mathrm{T}\left(\mathrm{x}_{1}\right)<$ малий, середній, великий>. 
Терм-множини значень лінгвістичних змінних

\begin{tabular}{|c|c|c|c|}
\hline Змінна & Лінгвістична суть змінної & $\begin{array}{l}\text { Універсальна } \\
\text { множина } \\
\text { значень } \\
\text { (множина D) }\end{array}$ & $\begin{array}{l}\text { Лінгвістичні терми } \\
\text { (множина Т) }\end{array}$ \\
\hline$x_{1}$ & Обсяг видання & $\begin{array}{c}(2-24) \text { фізичних } \\
\text { аркушів }\end{array}$ & $\begin{array}{c}\text { Малий, середній, } \\
\text { великий }\end{array}$ \\
\hline$x_{2}$ & Формат видання & $\begin{array}{c}(150 \times 210- \\
210 \times 270) \\
(315-567) \mathrm{cm}^{2}\end{array}$ & $\begin{array}{c}\text { Малий, середній, } \\
\text { великий }\end{array}$ \\
\hline$x_{3}$ & Тип зошита & $(1-5)$ у. о. & $\begin{array}{c}\text { Складний, неповний, } \\
\text { повний }\end{array}$ \\
\hline$x_{4}$ & Тип скріплення блоку & $\begin{array}{l}(2 \times 32-24 \times 32) \\
(64-768) \text { y. o. }\end{array}$ & $\begin{array}{c}\text { Клейовий, } \\
\text { комбінований шиттям } \\
\text { нитками }\end{array}$ \\
\hline $\mathrm{y}_{1}$ & $\begin{array}{c}\text { Спосіб комплектування } \\
\text { (кількість сторінок } \\
\text { видання) }\end{array}$ & $(4-768) c$. & Вкладанням, у підбір \\
\hline$y_{2}$ & $\begin{array}{c}\text { Фальцювання } \\
\text { (точність, якість) }\end{array}$ & $(1,5-3) \mathrm{MM}$ & $\begin{array}{c}\text { Низька, середня, } \\
\text { висока }\end{array}$ \\
\hline $\mathrm{y}_{3}$ & $\begin{array}{c}\text { Розкладання звороту } \\
\text { (точність суміщення, } \\
\text { якість) }\end{array}$ & $(0-2) \mathrm{MM}$ & $\begin{array}{c}\text { Низька, середня, } \\
\text { висока }\end{array}$ \\
\hline z & $\begin{array}{c}\text { Тип друкарської } \\
\text { машини }\end{array}$ & $(1-5)$ у. о. & Аркушева, рулонна \\
\hline
\end{tabular}

$$
A_{\text {малий }}\left(\mathrm{x}_{1}\right)=\left[\begin{array}{ccccc}
1 & 5 / 9 & 3 / 9 & 2 / 9 & 1 / 9 \\
9 / 5 & 1 & 3 / 5 & 2 / 5 & 1 / 5 \\
9 / 3 & 5 / 3 & 1 & 2 / 3 & 1 / 3 \\
9 / 2 & 5 / 2 & 3 / 2 & 1 & 1 / 2 \\
9 & 5 & 3 & 2 & 1
\end{array}\right] \cdot(7)
$$

Після розрахунку матриці (7) за програмою [12] отримаємо числові значення функцій належності для лінгвістичного терму «малий» стосовно задекларованих точок поділу:

$$
\begin{gathered}
\mu_{\text {малий }}\left(d_{1}\right)=0,45 ; \mu_{\text {малий }}\left(d_{2}\right)= \\
0,45=0,25 ; \mu_{\text {малий }}\left(d_{3}\right)=0,45= \\
0,15 ; \mu_{\text {малий }}\left(d_{4}\right)=0,45=0,1 ; \\
\mu_{\text {малий }}\left(d_{5}\right)=0,45=0,05 .
\end{gathered}
$$

Відносно терму «середній» матимемо матрицю:

$$
A_{\text {середній }}\left(x_{1}\right)=\left[\begin{array}{ccccc}
1 & 8 & 9 & 3 & 1 \\
1 / 8 & 1 & 9 / 8 & 3 / 8 & 1 / 8 \\
1 / 9 & 8 / 9 & 1 & 3 / 9 & 1 / 9 \\
1 / 3 & 8 / 3 & 9 / 3 & 1 & 1 / 3 \\
1 & 8 & 9 & 3 & 1
\end{array}\right] \cdot(8)
$$


Для терму «середній» 3 (8) дістанемо значення функцій належності.

$$
\begin{aligned}
& \mu_{\text {середній }}\left(d_{1}\right)=0,045 ; \\
& \mu_{\text {середній }}\left(d_{2}\right)=0,363 ; \\
& \mu_{\text {середній }}\left(d_{3}\right)=0,409 ; \\
& \mu_{\text {середній }}\left(d_{4}\right)=0,136 ; \\
& \mu_{\text {середній }}\left(d_{5}\right)=0,045 .
\end{aligned}
$$

Терм «великий» породжує матрицю

$$
A_{\text {великий }}\left(\mathrm{x}_{1}\right)=\left[\begin{array}{ccccc}
1 & 2 & 4 & 7 & 9 \\
1 / 2 & 1 & 4 / 2 & 7 / 2 & 9 / 2 \\
1 / 4 & 2 / 4 & 1 & 7 / 4 & 9 / 4 \\
1 / 7 & 2 / 7 & 4 / 7 & 1 & 9 / 7 \\
1 / 9 & 2 / 9 & 4 / 9 & 7 / 9 & 1
\end{array}\right] \text { (9) }
$$

Аналогічно попередньому 3 (9) для функцій належності отримаємо:

$$
\begin{aligned}
& \mu_{\text {великий }}\left(d_{1}\right)=0,043 ; \\
& \mu_{\text {великий }}\left(d_{2}\right)=0,086 ; \\
& \mu_{\text {великий }}\left(d_{3}\right)=0,173 ; \\
& \mu_{\text {великий }}\left(d_{4}\right)=0,304 ; \\
& \mu_{\text {великий }}\left(d_{5}\right)=0,391 .
\end{aligned}
$$

Здійснимо нормування функцій належності відносно одиниці, розрахувавши коефіцієнти нормування для ЛТ.

$$
\mathrm{k}_{1}=1 / \max \mu_{1}\left(d_{i}\right),(i=1, \ldots, 5),
$$

де I = «малий», «середній», «великий»; $\mu_{l_{n}}\left(\mathrm{~d}_{\mathrm{i}}\right)=\mathrm{k}_{\mathrm{l}} \times \mu_{1}\left(\mathrm{~d}_{\mathrm{i}}\right)$.

У результаті отримаємо такі нормовані значення функцій належності для всіх термів лінгвістичної змінної «обсяг видання»:

$$
\begin{gathered}
\mu_{\text {малий }}\left(d_{1}\right)=1 ; \\
\mu_{\text {малий }}\left(d_{2}\right)=0,55 ;
\end{gathered}
$$

$$
\begin{gathered}
\mu_{\text {малий }}\left(d_{3}\right)=0,33 ; \\
\mu_{\text {малий }}\left(d_{4}\right)=0,22 ; \\
\mu_{\text {малий }}\left(d_{5}\right)=0,11 ; \\
\mu_{\text {середний }}\left(d_{1}\right)=0,11 ; \\
\mu_{\text {середний }}\left(d_{2}\right)=0,89 ; \\
\mu_{\text {середній }}\left(d_{3}\right)=1 ; \\
\mu_{\text {середний }}\left(d_{4}\right)=0,33 ; \\
\mu_{\text {середнйй }}\left(d_{5}\right)=0,11 ; \\
\mu_{\text {великийn }}\left(d_{1}\right)=0,11 ; \\
\mu_{\text {великийn }}\left(d_{2}\right)=0,22 ; \\
\mu_{\text {великий }}\left(d_{3}\right)=0,44 ; \\
\mu_{\text {великий }}\left(d_{4}\right)=0,78 ; \\
\mu_{\text {великий }}\left(d_{5}\right)=1 .
\end{gathered}
$$

Пронормовані значення функцій належності ЛЗ «обсяг видання» використаємо для формалізованого подання лінгвістичних термів «малий», «середній», «великий» нечіткими множинами, загальний вигляд яких наведено у (2).

обсяг малий =

$=\left\{\frac{1}{2} ; \frac{0,55}{8} ; \frac{0,33}{14} ; \frac{0,22}{18} ; \frac{0,11}{24}\right\}$ фізич-

них аркушів;

обсяг середній = $=\left\{\frac{0,11}{2} ; \frac{0,89}{8} ; \frac{1}{14} ; \frac{0,33}{18} ; \frac{0,11}{24}\right\}$ фізичних аркушів;

обсяг великий = $=\left\{\frac{0,11}{2} ; \frac{0,22}{8} ; \frac{0,44}{14} ; \frac{0,78}{18} ; \frac{1}{24}\right\}$ фiних аркушів.

За отриманими результатами для лінгвістичної змінної «обсяг видання» будуємо суміщені графіки функцій належності стосовно лінгвістичних термів «малий», «середній», «великий» (рис.). 


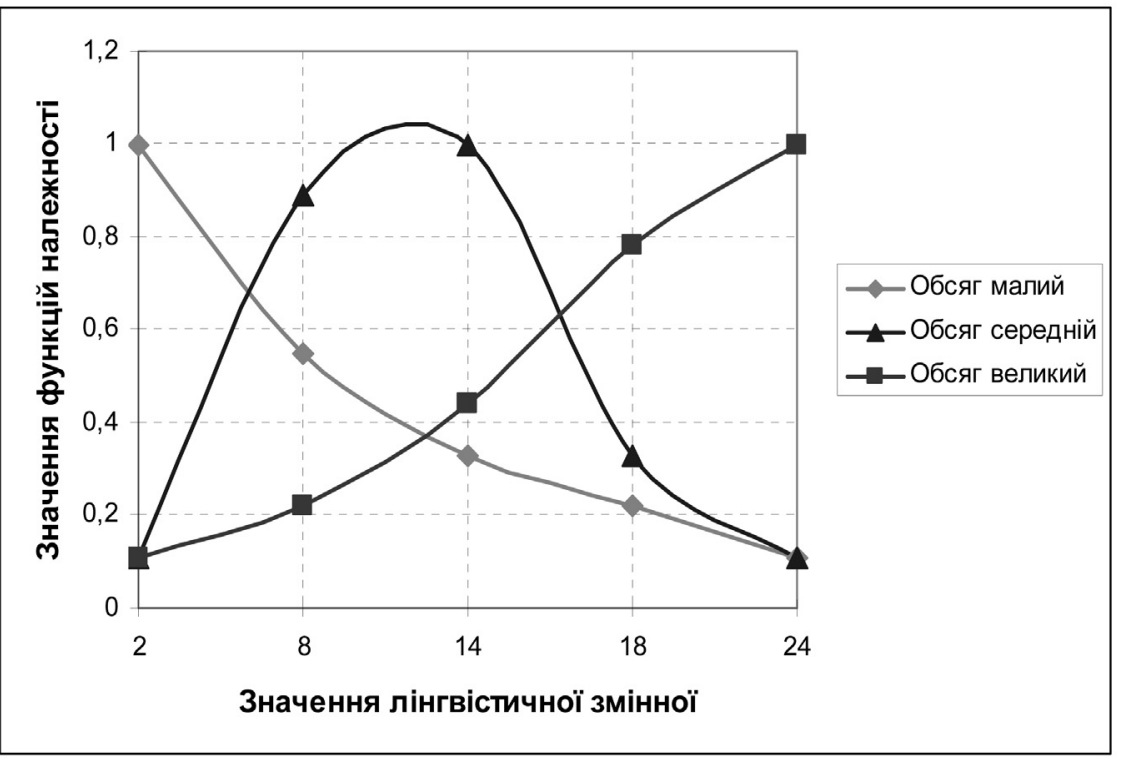

Функції належності лінгвістичної змінної «обсяг видання»

Розрахунок функцій належності для факторів, ідентифікованих лінгвістичними змінними табл., здійснюється аналогічно до наведеного вище алгоритму за скороченою схемою, тобто будуються матриці для всіх термів та відображаються остаточні результати через пронормовані значення функцій належності лінгвістичних змінних у вигляді формалізованого подання ЛТ нечіткими множинами і відповідні їм графіки - моделі візуального відображення значень функцій належності стосовно лінгвістичних термів.

Наведемо нечіткі множини пронормованих значень функцій належності для решти лінгвістичних змінних.

Лінгвістична змінна $\mathrm{x}_{2}$ «формат видання»: формат малий = $=\left\{\frac{1}{315} ; \frac{0,78}{338} ; \frac{0,33}{390} ; \frac{0,22}{472} ; \frac{0,11}{567}\right\} \mathrm{cm}^{2}$; формат середній = $=\left\{\frac{0,11}{315} ; \frac{0,44}{338} ; \frac{1}{390} ; \frac{0,78}{472} ; \frac{0,22}{567}\right\} \mathrm{CM}^{2}$;

формат великий = $=\left\{\frac{0,11}{315} ; \frac{0,22}{338} ; \frac{0,44}{390} ; \frac{0,66}{472} ; \frac{1}{567}\right\} \mathrm{cm}^{2}$.

Лінгвістична змінна $x_{3}$ «тип зошита»:

зошит складний =

$=\left\{\frac{0,11}{1} ; \frac{0,22}{2} ; \frac{0,78}{3} ; \frac{0,9}{4} ; \frac{1}{5}\right\}$ у. о.;

зошит неповний =

$=\left\{\frac{0,11}{1} ; \frac{0,22}{2} ; \frac{0,78}{3} ; \frac{0,9}{4} ; \frac{1}{5}\right\}$ у. о.;

зошит повний =

$=\left\{\frac{1}{1} ; \frac{0,86}{2} ; \frac{0,22}{3} ; \frac{0,11}{4} ; \frac{0,08}{5}\right\}$ y. o.

Лінгвістична змінна $\mathrm{x}_{4}$ «тип скріплення блоку»:

клейовий $=$

$=\left\{\frac{1}{64} ; \frac{0,33}{256} ; \frac{0,22}{416} ; \frac{0,11}{576} ; \frac{0,06}{768}\right\}$ y. o. 
комбінований = $=\left\{\frac{0,22}{64} ; \frac{1}{256} ; \frac{0,44}{416} ; \frac{0,33}{576} ; \frac{0,22}{768}\right\}$ у. о.; $\quad=\left\{\frac{1}{0} ; \frac{0,88}{0,5} ; \frac{0,16}{1} ; \frac{0,10}{1,5} ; \frac{0,06}{2}\right\}$ мм.

нитками = $=\left\{\frac{0,11}{64} ; \frac{0,44}{256} ; \frac{0,66}{416} ; \frac{0,89}{576} ; \frac{1}{768}\right\}$ y. o.

Лінгвістична змінна $\mathrm{y}_{1}$ «спосіб комплектування»: вкладанням = $=\left\{\frac{1}{4} ; \frac{0,33}{192} ; \frac{0,20}{384} ; \frac{0,11}{570} ; \frac{0,06}{768}\right\}$ сторіHOK;

$$
\text { впідбір = }
$$

$=\left\{\frac{0,04}{4} ; \frac{0,45}{192} ; \frac{0,70}{384} ; \frac{0,89}{570} ; \frac{1}{768}\right\}$ сторінок.

Лінгвістична змінна у 2 «фальцювання» (точність): точність низька $=$ $=\left\{\frac{0,11}{1,5} ; \frac{0,22}{1,9} ; \frac{0,6}{2,3} ; \frac{0,92}{2,7} ; \frac{1}{3}\right\}$ мм; точність середня = $=\left\{\frac{0,44}{1,5} ; \frac{0,9}{1,9} ; \frac{1}{2,3} ; \frac{0,44}{2,7} ; \frac{0,22}{3}\right\}$ мм; точність висока = $=\left\{\frac{1}{1,5} ; \frac{0,44}{1,9} ; \frac{0,16}{2,3} ; \frac{0,11}{2,7} ; \frac{0,06}{3}\right\}$ мм.

Лінгвістична змінна у $\mathrm{y}_{3}$ «розкладання звороту» (точність суміщення):

точність низька = $=\left\{\frac{0,11}{0} ; \frac{0,20}{0,5} ; \frac{0,28}{1} ; \frac{0,44}{1,5} ; \frac{1}{2}\right\}$ мм; точність середня = $=\left\{\frac{0,22}{0} ; \frac{0,44}{0,5} ; \frac{0,96}{1} ; \frac{1}{1,5} ; \frac{0,22}{2}\right\}$ мм;
Лінгвістична змінна z «тип друкарської машини»:

аркушева $=$

$=\left\{\frac{1}{1} ; \frac{0,90}{2} ; \frac{0,78}{3} ; \frac{0,22}{4} ; \frac{0,10}{5}\right\}$ у. о.;

рулонна $=$

$=\left\{\frac{0,06}{1} ; \frac{0,11}{2} ; \frac{0,22}{3} ; \frac{0,88}{4} ; \frac{1}{5}\right\}$ y. o.

\section{Висновки}

Отримані результати складають основу етапу фазифікації, у процесі якого формується універсальна множина значень виокремлених факторів лінгвістичних змінних та відповідних їм лінгвістичних термів.

На підставі отриманих вище значень функцій належності та моделі логічного виведення [10] проектується нечітка база знань та система нечітких логічних рівнянь - основа процесу дефазифікації, у результаті якого розраховується числове значення інтегрального показника прогнозованої якості формування монтажних спусків книжкових видань.

\section{Список використаної літератури}

1. Сеньківський В. М. Ранжування факторів впливу на якість формування монтажних спусків / В. М. Сеньківський, Т. С. Голубник // Поліграфія і видавнича справа. - Львів : УАД, 2013. - № 1-2(61-62). С. 51-57.

2. Заде Л. А. Понятие лингвистической переменной и его применение к принятию приближенных решений / Л. А. Заде. - М. : Мир, 1976. - 165 с. 
3. Заде Л. Роль мягких вычислений и нечеткой логики в понимании, конструировании и развитии информационных интеллектуальных систем / л. Заде // Новости искусственного интеллекта. - М., 2001. - № 2-3. С. 7-11.

4. Ротштейн О. П. Soft Computting в біотехнології : багатофакторний аналіз і діагностика : монографія / О. П. Ротштейн, Є. П. Ларушкін, Ю. І. Мітюшкін. - Вінниця : УНІВЕРСАМ-Вінниця, 2008. - 144 с.

5. Ротштейн А. П. Интеллектуальные технологи идентификации : нечеткие множества, нейронные сети, генетические алгоритмы / А. П. Ротштейн. - Винница : УНІВЕРСАМ-Вінниця, 1999. - 320 с.

6. Сявавко М. С. Інформаційна система «Нечіткий експерт» / М. С. Сявавко. - Львів : Видавничий центр ЛнУ імені Івана Франка, 2007. $320 \mathrm{c}$.

7. Штовба С. Д. Проектирование нечетких систем средствами MATLAB / С. Д. Штовба. - М. : Горячая линия - Телеком, 2007. - 288 с.

8. Бартіш М. Я. Дослідження операцій. Частина 3. Ухвалення рішень i теорія ігор / М. Я. Бартіш, І. М. Дудзяний. - Львів : Видавничий центр ЛНУ імені Івана Франка, 2009. - 278 с.

9. Зайченко Ю. П. Дослідження операцій. Підручник. Сьоме видання, перероблене та доповнене / Ю. П. Зайченко. - К. : Видавничий Дім «Слово», 2006. - 816 с.

10. Голубник Т. С. Засади нечіткої логіки при забезпечення якості формування монтажних спусків / Т. С. Голубник, І. В. Піх., В.М.Сеньківський // Наукові записки. Наук. техн. зб. - Львів : УАД, 2014. Вип. № 1-2(46-47). - С. 43-49.

11. Т. Саати. Принятие решений (Метод анализа иерархий) / Т. Саати. М. : Радио и связь, 1993. - 278 с.

12. Свідоцтво про реєстрацію авторського права на твір № 41832. Україна. Імітаційне моделювання в системному аналізі методом бінарних порівнянь. [Комп'ютерна програма] / Авторські майнові права належать І. В. Гілеті, В. М. Сеньківському, О. В. Мельникову. Зареєстровано 17.01.2012.

\section{References}

1. Senkivskyi V. M. Ranzhuvannia faktoriv vplyvu na yakist formuvannia montazhnykh spuskiv / V. M. Senkivskyi, T. S. Holubnyk // Polihrafiia i vydavnycha sprava. — Lviv : UAD, 2013. - № 1-2(61-62). - S. 51-57.

2. Zade L. A. Ponjatie lingvisticheskoj peremennoj i ego primenenie k prinjatiju priblizhennyh reshenij / L. A. Zade. - M. : Mir, 1976. - 165 s.

3. Zade L. Rol' mjagkih vychislenij i nechetkoj logiki v ponimanii, konstruirovanii i razvitii informacionnyh intellectual'nyh sistem / L. Zade // Novosti iskusstvennogo intellekta. - M., 2001. - № 2-3. - S. 7-11.

4. Rotshtein O. P. Soft Computting v biotekhnolohii : bahatofaktornyi analiz i diahnostyka : monohrafiia / O. P. Rotshtein, le. P. Larushkin, lu. I. Mitiushkin. Vinnytsia : UNIVERSAM-Vinnytsia, 2008. - $144 \mathrm{~s}$.

5. Rotshtejn A. P. Intellektual'nye tehnologi identifikacii : nechetkie mnozhestva, nejronnye seti, geneticheskie algoritmy / A. P. Rotshtejn. - Vinnica : UNIVERSAM-Vinnicja, 1999. - $320 \mathrm{~s}$.

6. Siavavko M. S. Informatsiina systema «Nechitkyi ekspert» / M. S. Siavavko. - Lviv : Vydavnychyi tsentr LNU imeni Ivana Franka, 2007. $320 \mathrm{~s}$. 
7. Shtovba S. D. Proektirovanie nechetkih sistem sredstvami MATLAB / S. D. Shtovba. - M. : Gorjachaja linija - Telekom, 2007. - 288 s.

8. Bartish M. la. Doslidzhennia operatsii. Chastyna 3. Ukhvalennia rishen i teoriia ihor / M. la. Bartish, I. M. Dudzianyi. - Lviv : Vydavnychyi tsentr LNU imeni Ivana Franka, 2009. - $278 \mathrm{~s}$.

9. Zaichenko lu. P. Doslidzhennia operatsii. Pidruchnyk. Some vydannia, pereroblene ta dopovnene / lu. P. Zaichenko. - K. : Vydavnychyi Dim «Slovo», 2006. - $816 \mathrm{~s}$.

10. Holubnyk T. S. Zasady nechitkoi lohiky pry zabezpechennia yakosti formuvannia montazhnykh spuskiv / T. S. Holubnyk, I. V. Pikh., V. M. Senkivskyi // Naukovi zapysky. Nauk. tekhn. zb. - Lviv : UAD, 2014. Vyp. № 1-2(46-47). - S. 43-49.

11. T. Saati. Prinjatie reshenij (Metod analiza ierarhij) / T. Saati. - M. : Radio i svjaz', 1993. - 278 s.

12. Svidotstvo pro reiestratsiiu avtorskoho prava na tvir № 41832. Ukraina. Imitatsiine modeliuvannia $v$ systemnomu analizi metodom binarnykh porivnian. [Komp'iuterna prohrama] / Avtorski mainovi prava nalezhat I. V. Hileti, V. M. Senkivskomu, O. V. Melnykovu. Zareiestrovano 17.01.2012.

Запроектированы функции принадлежности и осуществлено их графическое отображение для выделенных факторов влияния на качество формирования монтажных спусков книжных изданий. Построены матрицы парных сравнений, учитывающие определенные экспертами ранги факторов, посредством которых рассчитаны значения функций принадлежности для предложенных лингвистических термов в точках деления универсального множества значений лингвистических переменных. Осуществлено формализованное отображение лингвистического терма «качество монтажного спуска" с помощью нечеткого множества, содержащего значения функций принадлежности. Приведен пример графического отображения значений функций принадлежности лингвистической переменной “объем издания".

Ключевые слова: монтажный спуск, качество, фактор, лингвистическая переменная, функция принадлежности, терм-множество, матрица, ранг.

The functions of belonging are projected and their graphic reflection is carried out for the distinguished factors of influence on quality of forming of the assembling lowering of book editions. The matrices of pair comparisons, taking into account the certain experts grades of factors by means of that the values of functions of belonging are expected for the offered linguistic therms in points the division of universal set of values of linguistic variables, are built. The formalized reflection of linguistic 
therm is carried out "quality of the assembling lowering" by means of fuzzy set, containing the values of functions of belonging. An example of graphic reflection of values of functions of belonging of linguistic variable is made "volume of edition".

Keywords: assembling lowering, quality, factor, linguistic variable, function of belonging great, therm-number, matrix, grade.

Рецензент - О. М. Величко, д.т.н., професор, НТУУ «КПІ»

Надійшла до редакції 02.07.14 